\title{
NOTAS SOBRE A LINGUAGEM ESSENCIAL EM WALTER BENJAMIN1
}

Fabiano Barboza Viana

\section{RESUMO}

Em nosso percurso, pretendemos examinar o desenvolvimento da concepção benjaminiana de "linguagem essencial" em oposição à redução da linguagem aos seus aspectos comunicativos. Nos pautaremos por uma análise detida do ensaio, "Sobre a linguagem em geral e sobre a linguagem do homem" (1916). Como veremos, a concepção de uma linguagem essencial será responsável por lançar as bases de uma crítica histórica nos escritos de maturidade de Walter Benjamin.

Palavras-chave: Linguagem. Comunicação. Essência Espiritual.

\section{NOTES ON THE ESSENTIAL LANGUAGE OF WALTER BENJAMIN}

\begin{abstract}
Though our journey, we intend to examine the development of Benjamin's conception of "essential language" as opposed to the reduction of language to its communicative aspects. Our basis will be a careful analysis of the essay "On language in general and about the language of man" (1916). As we shall see, the concept of an essential language will be responsible for laying the foundations of historical criticism in the writings of Walter Benjamin in his maturity.
\end{abstract}

Keywords: Language. Communication. Spiritual Essence.

No presente ensaio irei me ater à perspectiva dos textos de juventude de Walter Benjamin, redigidos entre 1915 e 1921, mais ou menos contemporâneos a sua tese de doutorado de 1919 (O Conceito de Crítica de Arte no Romantismo Alemão) e ao ensaio sobre as Afinidades Eletivas de Goethe de $1922^{2}$. Textos estes, classificados por partes dos críticos, como "bastante elípticos, beirando o esoterismo" (Gagnebin apud Benjamin, 2011, p. 7). Tal classificação não deve ser considerada sem propósito, haja vista a dimensão "metafísica" desses textos de juventude, assim como, as correlações inusitadas entre teologia judaica, estudos da

\footnotetext{
1 Texto apresentado originalmente no Encontro de Pós-Graduação do Departamento de Filosofia da USP, em 2013.

2 Seguimos neste ensaio, em grande parte, a introdução, notas e comentários de Jeanne Marie Gagnebin presentes na edição brasileira de textos reunidos de juventude de Walter Benjamin: Escritos Sobre Mito e Linguagem, São Paulo, Editora Duas Cidade/34, 2011. Logo após, passamos a uma análise detida do ensaio Sobre a Linguagem em Geral e sobre a Linguagem do Homem.
} 
cabala, estética, política e reflexões sobre a linguagem ${ }^{3}$. Apenas a título de nota, lembremos que essa dimensão metafísica junto às correlações mencionadas, cruzará todo o pensamento de Benjamin reaparecendo em seus últimos escritos como as teses Sobre o conceito de história de 1940, nas quais Benjamin aborda "a problemática ao mesmo tempo crítico-hermenêutica e política do historiador materialista" (Ibidem, 2011, p. 10) ${ }^{4}$.

Feitas essas considerações preliminares, passemos ao objetivo central de nosso ensaio: compreender, em linhas gerais, a relação entre o espiritual e a linguagem no jovem Benjamin, num primeiro momento, para em seguida analisar aquilo que o filósofo chamou de "essência linguística do homem"5 e a decadência de seu poder inato de nomear.

Em carta de 1916 ao importante estudioso da mística judaica, Gershom Scholem, Benjamin referiu-se ao ensaio intitulado Sobre a linguagem em geral e sobre a linguagem do homem do seguinte modo: “(...) neste trabalho, busco confrontar-me com a essência da linguagem e certamente, tanto quanto posso

3 Tais "correlações" podem ser absorvidas numa ideia fundante de Walter Benjamin, já exposta em sua tese de 1919 e desenvolvida nos escritos de maturidade - a ideia de Constelação (Konstellation). Para o autor "as ideias se relacionam com as coisas como as constelações com as estrelas", de modo que a "relação entre seus componentes, as estrelas, não seja apenas motivada pela proximidade entre elas, mas também pela possibilidade de significado que Ihes pode ser atribuída" (Otte; Volpe, 2000, p. 37). Sendo assim, a constelação extrai os significados dessas "estrelas-mortas", feitas saberes antiquíssimos, em novas configurações inusitadas do presente. Opera aqui a ideia de extremo (Benjamin: 1984) em que o uso das palavras configuram um arco equidistante entre os significados mais remotos e os deslocamento dados presentes. Não há um centro do significado, uma vez que é o próprio processo do "singular-extremo" que caracteriza carga significativa das palavras (Otte; Volpe, 2000, p.38). Por isso, muitos dos estudiosos de Benjamin irão afirmar a existência de uma unidade do pensamento benjamiano, para além desses cortes entre um Benjamin "metafísico" e um Benjamin "materialista". Verificamos essa continuidade através do uso do termo constelação que implica diretamente reconfiguração entre teologia judaica e materialismo histórico: "O discurso benjaminiano ganharia, assim, aspectos constelares, uma vez que o uso do mesmo termo em textos cronologicamente e ideologicamente distantes estabelece uma ligação entre eles. Assim, o termo constelação, que ocupa um lugar importante nas "Questões introdutórias..." de 1925, pode ser re-encontrado em suas reflexões sobre a história, tanto nos respectivos fragmentos da chamada Obra das Passagens (Das Passagen-Werk), quanto em seu último texto, de 1940" (Ibidem, p. 38). Lembremo-nos da afirmação de Benjamin logo em sua primeira Tese sobre o materialismo histórico: "pode enfrentar qualquer desafio, desde que tome a seu serviço a teologia" (Benjamin, 1985, 222). Haveria assim "uma certa neutralização da tradicional distância entre o marxismo e a teologia e é de se perguntar, se não há uma certa ironia por trás dessa constelação" (Otte; Volpe, 2000, p.38). Isto demonstraria que os primeiros temas benjaminianos não serão esquecidos ao longo desenvolvimento de sua experiência intelectual.

${ }^{4}$ Esta síntese levará, entre outras coisas, àquilo que Leandro Konder denominou "marxismo da melancolia": "a esperança ficava relegada a um horizonte distante, onde podia ser enxergado seu brilho messiânico, porém não funcionava como mola impulsionadora para a paciente realização das tarefas políticas do dia-a dia" (Konder,1988,102).

5 "Linguística" refere-se à forma adjetivada do substantivo Sprache, sprachlich. Márcio SilegmannSilva em seu Ler o Livro do mundo. Walter Benjamin: romantismo e crítica poética, São Paulo, lluminuras, 1999 optou por traduzir este termo por meio do neologismo "lingual". 
compreender, numa relação imanente com o judaísmo, em especial com o primeiro capítulo do Gênesis (...). Pelo título, Sobre a linguagem em geral e sobre a linguagem do homem, você pode perceber certa intenção sistemática, que me parece, porém, tornar evidente também o caráter fragmentário do pensamento" (Benjamin, 2011, p. 162) ${ }^{6}$. Neste primeiro depoimento, Benjamin justifica o retorno ao problema da linguagem, porém pensada numa relação imanente com as questões da religião judaica. Desloca-se da compreensão da linguagem associada ao sempiterno logos grego em direção à abordagem ligada ao problema das origens, conforme proposto pela mística judaica (via romantismo alemão) ${ }^{7}$. Benjamin ainda contrapõe dialeticamente a intenção de sistematicidade desse pensamento à sua realização fragmentária, isto é, as expectativas de um pensamento unitário acabam por evidenciar a não efetuação do mesmo.

No ano seguinte, em carta a Ernst Schoen, reinsere a questão: "para mim a dúvida sobre a essência do conhecimento, do direito e da arte é inseparável daquela sobre a origem de cada expressão espiritual humana pela essência da linguagem (...). Você já conhece meu trabalho de 1916 sobre 'a linguagem em geral e a linguagem do homem'(...). Ele constitui para mim o ponto de partida para um trabalho mais amplo (...)" (Ibidem, pp. 162-163). Este último depoimento confirmaria

${ }^{6}$ A ideia de constelação, que assinalamos a pouco, precisará lidar posteriormente com o problema da fragmentação do pensamento. Além do retorno ao problema das origens, trata-se de reunir transversalmente todas as conexões de ideias e coisas, por meio de uma estrutura supra-linear. Daí a necessidade de uma distância contemplativa para reunir os fragmentos dos mosaicos do texto, da história e do conhecimento. Diz Benjamin: "Incansável, o pensamento começa sempre de novo, e volta sempre, minuciosamente, às próprias coisas. Esse fôlego infatigável é a mais autêntica forma de ser da contemplação. Pois ao considerar um mesmo objeto nos vários estratos de sua significação, ela recebe ao mesmo tempo um estímulo para o recomeço perpétuo e uma justificação para a intermitência do seu ritmo. Ela não teme, nessas interrupções, perder sua energia, assim como o mosaico, na fragmentação caprichosa de suas partículas, não perde sua majestade. Tanto o mosaico como a contemplação justapõem elementos isolados e heterogêneos, e nada manifesta com mais força o impacto transcendente, quer da imagem sagrada, quer da vontade. $O$ valor desses fragmentos de pensamento é tanto maior quanto menor sua relação imediata com a concepção básica que Ihes corresponde"(Benjamin, 1984, 50-51).

7 Evidentemente trata-se de um momento muito diverso daquele de Johann Herder em seu Ensaio sobre a origem da linguagem. Neste ensaio seminal Herder estabelece os fundamentos de uma linguagem humana distinta tanto da "linguagem animal" quanto de qualquer especulação sobre uma "linguagem divina". O ato humano da reflexão não se reduz a um ato lógico de julgar, visto ser inseparavelmente um ato "de linguagem". O homem conhece por meio de "distinções" e esta implica não apenas num processo tradicional de predicação, mas naquilo que chamou de "palavra na alma" (Herder, 1987, p. 56). Assim, a origem da linguagem se confunde com este ato próprio da constituição de uma antropologia. Estabelecida esta reciprocidade entre homem e linguagem, ampliação do domínio humano se efetiva por meio do "enriquecimento da linguagem", por meio do aprendizado da língua, das palavras. Benjamin por pressupor uma "linguagem divina" operará também com a categoria de "restituição" da linguagem, como veremos. 
a um só tempo a ideia de que a origem da "expressão espiritual humana" pode ser compreendida por uma visada sobre a "essência da linguagem" e a ideia de que o espírito humano manifestado nas diversas expressões humanas carrega necessariamente consigo essa linguagem essencial. Por conta disso, a problemática da linguagem original permaneceria, por vezes de modo velado, nos trabalhos ditos mais "materialistas" de Benjamin, elaborados a partir de 1924, como nas análises literárias, estéticas, históricas, sociais e políticas (Gagnebin apud Benjamin, 2011, p. 10).

Concentremos-nos então no ensaio de 1916. Este tem como premissa uma compreensão de que toda "manifestação da vida espiritual" (humana e na natureza) atua em um tipo de "linguagem", Comecemos pelo segundo termo. Embora o conceito de "linguagem" (sprache) também opere na língua alemã a distinção tradicional entre homens e animais, baseada no pressuposto de que o diferencial humano seria a posse de uma linguagem (sprache) "verbal e articulada" dotada de um sentindo imanente, não se pode reduzi-la exclusivamente ao domínio da língua verbal humana. Assim, esta linguagem será compreendida como expressão de uma dimensão espiritual que ultrapassa os diferentes idiomas e códigos humanos, uma vez que esta também se apresenta entre os animais, como na fórmula "linguagem dos pássaros". Com efeito, esta linguagem, manifestação da vida espiritual, seria o meio de aproximação dos diversos seres do mundo; no caso específico dos homens, tal linguagem ressoaria no fundo das diferentes línguas e códigos, como no exemplo fornecido por Benjamin: "pode-se falar (...) de uma linguagem da jurisprudência que nada têm a ver, imediatamente, com as línguas que estão redigidas as sentenças dos tribunais ingleses e alemães; pode se falar de uma linguagem da técnica que não é a linguagem específica dos técnicos” (Benjamin, 2011, p. 49). Contudo, se a linguagem tomada como manifestação da vida espiritual se distribui e dissemina pelo mundo, isto não acarreta que exista uma unidade do espiritual - antes, há uma multiplicidade de manifestações espirituais (e não exatamente do "Espírito", como em Hegel) que se expressam como linguagem, como nos exemplos das linguagens jurídicas e técnicas. Sendo assim, "a linguagem", "significa o princípio que se volta

\footnotetext{
8 O termo em alemão é Sprache. Possui igualmente as acepções de "língua" e "idioma" que aparecerão no texto de Benjamim. Devemos ainda fazer nota sobre a larga fortuna do termo no romantismo alemão e no desenvolvimento da linguística histórica, como vimos no ensaio de Herder.
} 
para a comunicação de conteúdos espirituais nos domínios em questão: na técnica, na arte, na jurisprudência ou na religião" (Ibidem, p. 50).

Se a expressão verbal é apenas um caso particular da comunicação de conteúdos espirituais por meio da linguagem, uma contra hipótese geral aventada por Benjamin afirma que em que todos os aspectos da vida há comunicação de conteúdos espirituais por meio de linguagem. A linguagem assim participaria de todos os "eventos e coisas", uma vez que a ideia de uma ausência de espírito é mutiladora da complexidade do real enquanto a ideia de uma ausência de linguagem se faz irrepresentável. Benjamin seria então movido pela metafísica da língua alemã.

Logo, uma expressão particular qualquer se refere a sua essência "linguística" (sprachlich) específica a qual, por sua vez, também se reporta a uma essência espiritual específica. Benjamin é levado à afirmação de que "a língua alemã", "não é, em absoluto, a expressão de tudo o que podemos - supostamente - expressar através dela, mas, sim, a expressão imediata daquilo que se comunica dentro dela" (Ibidem, p. 51). Estamos em outro lugar, por exemplo, daquele próprio à concepção estruturalista de linguagem na qual a relação entre o signo linguístico e o referente é tomada como fundamentalmente convencional. Aqui, a língua, em suas várias expressões, funciona como uma abertura para conteúdos espirituais próprios se associados (no sentido de adequados), embora podemos igualmente depreender da afirmação de Benjamin simplesmente a ideia corrente de que cada língua traz consigo uma determinada constituição de mundo.

Isto não significa, e isto será o principal, que para Benjamin as essências espirituais devam ser confundidas de imediato com suas respectivas línguas e linguagens. Mesmo que acompanhem seus conteúdos espirituais, essas não assumem a espiritualidade como a própria essência, o que apontaria, apenas num primeiro momento, para certa exterioridade da última. Benjamin propõe assim um duplo essencialismo posto em paralelo: a essência da linguagem e a essência espiritual $^{9}$. Com isso, no coração da identidade entre linguagem e conteúdo se instaura paradoxalmente uma diferenciação incontornável a qual, de um lado, afirma a transcendência da espiritualidade e, de outro, a densidade da própria linguagem ${ }^{10}$.

\footnotetext{
${ }^{9}$ Embora, como veremos, Benjamin elabore um jogo de dupla participação das essências, uma essência operando como essência da outra numa relação de reciprocidade.

${ }^{10}$ Tal distinção será importante no final do ensaio quando passar a uma constatação da reificação da natureza junto a um tipo de alienação da linguagem.
} 
Assim, nos afasta do logos platônico ao conferir positividade à linguagem, bem como, quando postula uma dupla essência - senão um múltiplo essencialismo.

Assumida a consistência dessas duas instâncias, pode-se afirmar que, em si mesma, a essência espiritual a partir de sua autonomia se manifesta na língua e não por meio desta, isto é, a língua (e a expressão) age como espaço de vazão da espiritualidade, sem que seja totalmente ativa, embora este espaço nunca seja aleatório ou arbitrário. O único ponto de identidade entre as duas essências se daria no fato de que a espiritualidade em essência é comunicável, propriedade fundamental da linguagem. Aqui o filósofo poderá reatar as duas essências: a comunicação da espiritualidade "dentro", e não através, da linguagem apenas se torna possível porque, neste ponto, a essência linguística espiritual participa da essência linguística de modo vivo. Em outras palavras, a espiritualidade coloca-se a si própria na linguagem, porém esse movimento tem como condição de possibilidade o caráter genético do espiritual de se fazer linguagem, de se manifestar em uma realidade outra, situação que veremos inviabilizada após a queda do paraíso.

Portanto, a linguagem "comunica a essência linguística das coisas" (Ibidem, p. 52) que não deixa de ser a própria linguagem, a própria linguagem da coisa. Por sua vez, a "essência espiritual" somente é expressa na medida em que participa da essência linguística das coisas, isto é, assume sua potencialidade de ser comunicável (Ibidem, p. 52). Todavia as coisas, do ponto de vista de suas essências na linguagem, e entendidas como suas expressões ou comunicações na linguagem (conceituais ou não, mais uma diferença em comparação com os gregos clássicos), não deverá ser reduzida a tautologia de que a linguagem em abstrato comunica a própria linguagem. Conforme dito, a essência espiritual na medida em que participa da essência linguística torna-se determinante na conformação do sentido das coisas. Esse elemento comunicável, dado na parcela do espiritual que converge como linguístico, não terá mediações, segundo Benjamin (Ibidem, p. 52). Essa parcela subscrita será o último bastião de identidade: fixa-se assim o ponto no qual o espiritual é comunicável e, portanto se faz imediatamente enquanto linguagem; este é exatamente o ponto no qual a linguagem/língua encontra-se a si mesma, a saber: o espiritual na sua parcela linguística, comunicável. Conforme o filósofo: "toda língua se comunica em si mesma; ela é, no sentido mais puro, o meio (medium) da comunicação" (Ibidem, p. 53). O termo medium em alemão, ao contrário de mittel 
não conserva um sentido instrumental, mediatizado, indicando apenas um modo, uma relação. Sendo assim, a língua comunica em si mesma essa manifestação da espiritualidade sem mediações ou exterioridade referencial, ao que Benjamin chamará de comunicação mágica, igualmente esfacelada na modernidade.

Como aquilo que se comunica essencialmente na língua nada mais é que a espiritualidade na sua dimensão linguística (lembrando que linguístico aqui significa "de linguagem"), esta não poderá ser "limitada e nem medida do exterior" (Ibidem, p. 54) pelos aspectos verbais da língua. Será na infinitude de seu interior (noção remetida a outra noção, aquela de magia) que se inscreverá suas potencialidades. Por isso o filósofo irá insistir que nada se comunica através da língua, como se a mecânica verbal estivesse programada para a representação de conteúdos exteriores, mas que algo se comunica na língua, nos remetendo ao ponto de intersecção entre linguagem e espiritualidade Encontro das essências: nem abstração linguística, nem transcendência inefável.

Passemos ao segundo movimento de nossa exposição. Segundo Benjamin, "a essência linguística do homem é a sua língua. Isso quer dizer que o homem comunica sua própria essência espiritual na sua língua" (Ibidem, p. 54). Ora, o surpreendente do homem seria ter como essência linguística/espiritual justamente um modo especial de linguagem que é a língua. Como a língua do homem "fala em palavras", o "ser humano comunica" sua essência "ao nomear todas as outras coisas" (Ibidem, p. 54), ou seja, a essência do homem é "nomear as coisas" (Ibidem, p. 55) o que eleva seu estatuto diante da linguagem em geral.

A despeito disso, permanece aqui aquela concepção que Benjamin desenvolveu ao tratar da linguagem em geral: mesmo que do ponto de vista burguês o homem comunique a si mesmo (que seja assim o alvo da comunicação), e que essa comunicação se dê por meio de palavras, se referindo a objetos, essencialmente, o homem comunica-se não através do ato de nomear, mas no ato de nomear. Da mesma forma, a palavra não é voltada para o exterior, isto é, não é como um meio instrumental (mittel) que deveria desvelar a essência espiritual do homem, sendo que o próprio nome em si (e não meramente projetado na ação de nomear da palavra) deve manifestar a essência espiritual do homem. Logo, Benjamin oferece uma outra concepção na qual "no nome a essência espiritual do homem se comunica a Deus" (Ibidem, p. 55). "Essência da própria língua", o nome 
faz com que a própria língua se comunique a si mesma de modo absoluto (Ibidem, p. 56). O nome tomado reflexivamente manifesta a essência espiritual do homem que é a língua, perspectivada aqui como um absoluto fora das relações historicistas de designação de eventos e coisas ${ }^{11}$. Desse ponto de vista, a essência espiritual do homem não será compreendida através da relatividade do nomear, mas considerada em meio à totalidade de criação, cujo "nome" torna-se a abertura.

Essa passagem fornece um lugar privilegiado ao homem: o nome ao realocar o homem no plano da criação faz com que o mesmo seja o único ser, "cuja essência espiritual é plenamente comunicável" (Ibidem, p. 56). Ao nomear, "a totalidade intensiva da língua" emerge; não se atravessa a língua, mas dentro dela se comunica a própria língua que se abre para o mundo espiritual. Por consequência, toda natureza se manifesta no homem com os nomes. A partir de uma concepção notadamente herdeira da tradição judaica o homem se tornar senhor da natureza por compartilhar o dom divino de nomear que nada mais é que conhecer o nome próprio das coisas, suas essências, como no princípio Adão, antes da queda, conhecera. De mesma forma, por estar apto a desvendar o verdadeiro nome, o homem passa a assumir o papel de co-autor da criação.

Assim, apesar da linguagem ser uma propriedade objetiva manifesta no mundo e, ao mesmo tempo, manifestação da espiritualidade, o único falante existente é o homem, ou seja, aquele que em última instância é apto em tomar consciência da linguagem, do espiritual. Igualmente, o homem é aquele ser capaz de conhecer e expressar nas coisas seu nome intensivo e universal: movimento intensivo reconduzido ao essencial da linguagem, mas também domínio sobre a faculdade extensiva da nomeação ${ }^{12}$.

Sobre a revelação, Benjamin defende a tese de que o mais alto grau da espiritualidade é aquele que se dá na intersecção com a linguagem. Pois nele, seguindo mais uma vez a interpretação judaica das escrituras, repousa o verbo bíblico em sua pureza e plenitude. As marcas da criação, entretanto, encontram-se

\footnotetext{
${ }^{11}$ Exploraremos num trabalho posterior as semelhanças e diferenças com a noção de desvelamento do Ser do Ente presente na obra Ser e Tempo de Martin Heidegger.

${ }^{12}$ Lembremo-nos como no Velho Testamento, Deus revela toda extensão espaço-temporal da criação ao mesmo tempo em que domina cada coisa e o conjunto das coisas em seu íntimo por meio do ato de nomear: "E disse Deus: Haja luz; e houve luz. E viu Deus que era boa a luz; e fez Deus separação entre a luz e as trevas. E Deus chamou à luz Dia; e às trevas chamou Noite. E foi a tarde e a manhã, o dia primeiro" (Gênesis 1:3-5).
} 
imperfeitas e apagadas no domínio da materialidade das coisas, o que exige desse investigador o retorno à realidade mais elevada e esquecida do nome. Esta realidade da linguagem resguarda uma distância e um potencial revolucionário que Benjamin irá desenvolver em seus escritos posteriores - a linguagem anuncia uma comunidade mágica sob a égide do símbolo a qual ultrapassa o silêncio material instituído na comunidade de coisas $^{13}$.

Por ventura, será o texto bíblico que levará às últimas consequências essa concepção da natureza espiritual da linguagem. Benjamin postula que esse tipo de reflexão deve ser respaldada, sobretudo, porque toma a linguagem como uma realidade e permite investigá-la no seu pleno desenvolvimento e em seus fatos fundamentais. No Gênesis serão propostas de maneira lapidar a valorização da dignidade humana em meio à criação, a relação intrínseca entre criação e linguagem, e a justa medida entre nomear e conhecer. Pelo fato do homem articular uma língua que reconhece a espiritualidade manifesta - algo inacessível para as outras linguagens - o mesmo torna-se potencialmente apto a conhecer "na mesma língua que Deus cria" (Ibidem, p. 60). O homem se dirige ao conhecimento da linguagem das linguagens: a linguagem adâmica, na qual a essência manifesta de Deus se exerce - pois este não será, nas sagradas escrituras, pura criação em ato? Porém, se a palavra divina era dotada da faculdade de criar, resta ao homem conhecer de modo imperfeito por meio do ato de nomear, num mundo em que tal língua primeira se afastou completamente. Daí a pertinência do mito da torre de babel e suas as múltiplas línguas incomunicáveis entre $\mathrm{si}^{14}$.

\footnotetext{
${ }^{13}$ Segundo estudiosos da obra de Walter Benjamin, como Michael Löwy, os trabalhos do filósofo entre os anos 1910 e início dos anos 1920 estão fundamentados num retorno a Cabala e a língua hebraica através de uma mediação com o mito de uma linguagem essencial ou linguagem adâmica. Todavia, esse retorno não deve ser compreendido como uma tentativa de "interrupção da roda história"; antes funciona como um horizonte normativo e um conjunto de utopias messiânicas/restitucionistas alinhavadas posteriormente a crítica marxista.Tal leitura históricocosmogônica permitiria o aclaramento do caráter fragmentário do mundo e do pensamento, da dissolução do conhecimento, e da mecanização do trabalho conforme evidenciados na modernidade (Löwy: 1989).

${ }^{14}$ Conta-se no texto bíblico, que os homens na horizontalidade de suas vidas mundanas compartilhavam a mesma língua. Entretanto, procuraram construir umatorrecom o fim de atingirem os céus, morada de Deus. Uma vez edificada esta "torre humana", os homens já não podiam mais se comunicar entre sidevido a distância entre os que estavam na parte de baixo e os que estavam em cima. Múltiplas línguas eram inventadas por estes homens que não se lembravam mais da "língua das coisas", da "língua do criador". Por fim, Deus pôs ao chão a ignóbil Torre, fazendo com que os homens decaíssem no mundo das múltiplas culturas, das aparências, da incomunicabilidade. Após a queda no mais completo relativismo, as tentativas de retorno ao jardim original tornaram-se igualmente perigosas. Como bem lembra Michel Löwy os primeiros escritos de Benjamin sobre teologia judaica são inspirados pelo romantismo alemão. Em 1917, através das
} 
Neste contexto de degradação, é preciso, porém, ressaltar o caráter de resistência em relação à "concepção burguesa da língua" (Ibidem, p. 61) por meio dessa interpretação da linguagem. Pela palavra o homem em sentido pleno se vincula a imanência espiritual das coisas, mesmo que de modo imperfeito.Enquanto isso,o homem burguês apenas possui trânsito em meio às relações convencionais entre o signo e a coisa significada, aquilo que é da ordem exterior própria ao entendimento e o inventário científico. Por outro lado, a concepção burguesa não é completamente refutada, visto que nessa teoria da linguagem essencial o máximo que se tem é uma "receptividade ativa", já que a palavra do homem não é criadora como a palavra divina. Assim, apesar dessa palavra humana ir de encontro à "linguagem das coisas mesmas", esta se acha bloqueada, na "magia muda da natureza". Auscultam-se as coisas, mas aquilo que é expresso apenas pode se fazer ouvir de modo enviesado, em nosso paraíso perdido no qual ato criador não tem mais lugar (embora permaneça vivo na condição de ruínas). Assim, como para as personagens de Franz Kafka, diante da Lei, do Processo, do Castelo ou da assustadora América, resta aos homens apenas a interpretação infinita, a tradução, a dúvida implacável e a incomunicabilidade. A despeito da negatividade deste processo, o contínuo investimento nas múltiplas traduções precisa apostar na possibilidade de ampliação do conhecimento, trazendo a lume, por vezes, aquilo que

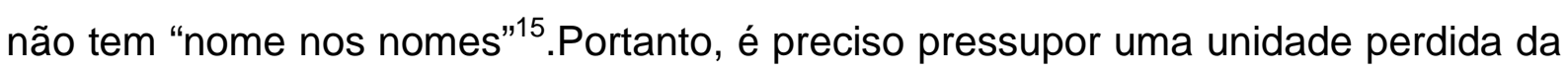
criação para se avaliar o preço daquilo que se perdeu junto ao desastre do mundo presente, bem como, recuperar o mundo das coisas de sua afasia, reconhecendo os potenciais emancipatórios de certos fragmentos da realidade. Ao mesmo tempo, não se pode escamotear a experiência do afastamento da língua primeira (o pecado original), e a cisão fundamental do homem em relação ao mundo das coisas. Com efeito, "a ideia reguladora" de uma linguagem essencial faz com que percebamos

suas discussões com G,Scholem, estudioso do judaísmo, e das leituras dos escritos do cabalista cristão Franz Joseph Molitor começa a trabalhar diretamente com as fontes da cultura judaica (Löwy, 1989, p.86). O mito da torre de babel contribuiria para ideia de uma "língua divina ideal anterior à deterioração histórica especifica de cada idioma. Benjamin chega, assim, à noção transnacional e a-histórica de uma "linguagem enquanto tal"” (Löwy, 1989, p. 86). O próprio Benjamin afirmaria que o texto bíblico "ao pressupor a linguagem como uma realidade fundamental, inexplicável e mística, perceptível apenas através de sua manifestação"(Benjamin apud Löwy, 1989, p. 86).

${ }^{15} \mathrm{Em}$ outra chave, Benjamin posteriormente a este período inicial investigará os vestígios desses materiais esquecidos em sua história da fotografia, dos brinquedos, no tema do poeta decaído na multidão nas notas sobre Baudelaire, na perda aura da obra de arte, nos projetos inconclusos das passagens parisienses etc. 
que a magia imanente das coisas reivindicada é visada a partir de seu exterior, por meio de mediações, abstrações e desvios.

Com isso a última inversão operada no ensaio. Se houve uma queda do paraíso e as línguas se multiplicaram a partir do afastamento da língua original, o homem já não é mais capaz de nomear a natureza a partir de seu nome próprio, de forma que "a devolução de uma dignidade ontológica subjetiva" à natureza passa a transformá-la num "objeto a ser dominado e explorado, a natureza é condenada ao silêncio e ao luto" (Lages apud Benjamin, 2011, p. 70). Diagnóstico, aliás, muito próximo aquele de Adorno em sua Dialética do Esclarecimento. O nome próprio se transforma numa falsa identidade que emudece sobremaneira a natureza desencantada e agora constrangida. As línguas humanas assim não falam mais a língua das coisas ${ }^{16}$.

Tão logo, na medida em que o homem precisa traduzir a língua muda da natureza, a qual já não mais acessa em seu verdadeiro nome, este fica fadado ao julgamento (índice de afastamento do plano da criação), que passa a circunscrever por meio de uma magia profana o nome própria da natureza e do homem, quiçá do próprio Deus.

\section{Algumas considerações finais}

Para Walter Benjamin, a palavra não deve ser admitida como uma "ideia transcendente" apreensível apenas por meio de uma "intuição intelectual". A ideia assim "é algo de linguístico, é o elemento simbólico presente na essência da palavra" (Benjamin apud Alter, 1992, p. 248). De outra parte, a linguagem, do ponto de vista de sua essência, ultrapassa a função mundana de comunicação:

\section{(...) pois todo o corpo da natureza está impregnado de uma linguagem sem nome e muda, resíduo da palavra criadora de Deus, que é percebida no homem como o nome que guia o conhecimento, e acima dele, como um julgamento suspenso sobre a sua cabeça ${ }^{17}$.}

No entanto, o ensaio de 1916 já lidará como uma questão central para o pensamento de Benjamin: a degradação da experiência humana, aqui, porém, sob o

\footnotetext{
${ }_{17}^{16}$ As discussões em voga sobre o tema da ecologia mostram muito bem isso.

${ }^{17}$ LÖWY, 1989, p. 87.
} 
prisma do totalitarismo da linguagem comunicativa. Como lembra Rouanet, "a palavra", "cede lugar a frase":

O verbo que penetra as coisas e através do qual elas falam é substituído pela proposição, graças à qual os homens falam sobre as coisas, atribuindo-Ihes, abstratamente, propriedades, através de atos de julgamento $^{18}$.

Esta condição "degradada" ajudará compreender o posterior marxismo heterodoxo do filósofo. Uma suposta teleologia do processo histórico que atravesse os problemas da fragmentação da experiência original, da cisão entre cria e conhecer, e que não lide com a perda "do descomunal impulso mimético da palavra" em proveito do refinamento da dimensão comunicativa, tenderá ao fracasso ${ }^{19}$. Neste sentido, esse ideário restitucionista, alicerçado no problema da origem da linguagem, irá contribuir para orientação da análise histórica posterior do filósofo, a procura dos elementos críticos que sobreviveram em negativo na concha de retalhos do presente.

\footnotetext{
${ }^{18}$ ROUANET, 1981, pág.118.

${ }^{19}$ Como demonstra Löwy no estudo citado: "Após a assimilação da perspectiva marxista, nos anos 30, os fenômenos da degradação da dimensão nomeadora da linguagem e do uso crescentemente instrumental das palavras, em função comunicativa, passaram a ser analisados por Benjamin menos em decorrência do pecado original e da expulsão do paraíso do que em consequência da ascensão da burguesia e do modo de produção capitalista. Persistiu, porém, a firme convicção de que as linguagens "primitivas", "sensoriais", desfrutam de um "tesouro" ao qual não chegamos a ter realmente acesso, na medida em que nos servimos - nas condições atuais- de um instrumental preciso, porém gerador de abstratividade" (Löwy: 1989).
} 


\section{REFERÊNCIAS}

ALTER, Robert. Anjos Necessários. Tradição e Modernidade em Kafka, Benjamin e Scholem. Trad. André Cardoso. Rio de Janeiro: Ed. Imago 1992.

BENJAMIN, Walter. Über Sprache überhaupt und über die Sprache des Menschen" In: Gesammelte Schriften. Bd. II (Aufsätze, Essays, Vorträge).Frankfurt am Main: Suhrkamp, 1977.

Origem do drama barroco alemão. Trad. Sérgio Rouanet.

São Paulo: Brasiliense, 1984.

Magia e Técnica, Arte e Política: ensaios sobre literatura e história da cultura. Trad: Sergio Paulo Rouanet; São Paulo: Ed Brasiliense, 1985.

Editora 34; Duas Cidades, 2011.

GAGNEBIN, Jeanne Marie. História e narração em Walter Benjamin. São Paulo: Unicamp, 1994.

HERDER, JOHANN GOTTFRIED. Ensaio sobre a origem da linguagem. Trad. José M. Justo. Edições Antígona: Lisboa, 1987.

KONDER,Leandro. O marxismo da melancolia. Rio de Janeiro, 1988.

LÖWY, Michael. Redenção e Utopia. O judaísmo libertário na Europa central. Trad. Paulo Neves. São Paulo: Companhia das Letras,1989.

OTTE, Georg; VOLPE, Miriam Lídia.Um olhar constelar sobre o pensamento de Walter Benjamin.In: Fragmentos, número 18, p. 35/47 Florianópolis/ jan - jun/ 2000.

ROUANET, Sérgio Paulo. Édipo e o anjo: itinerários freudianos em Walter Benjamin.Rio de Janeiro: Tempo Brasileiro, 1981.

SCHOLEM, Gershom. A mística judaica. São Paulo: Perspectiva, 1974.

SELIGMANN-SILVA, Márcio. Ler o livro do mundo: romantismo e crítica literária. São Paulo: lluminuras, 1999. 